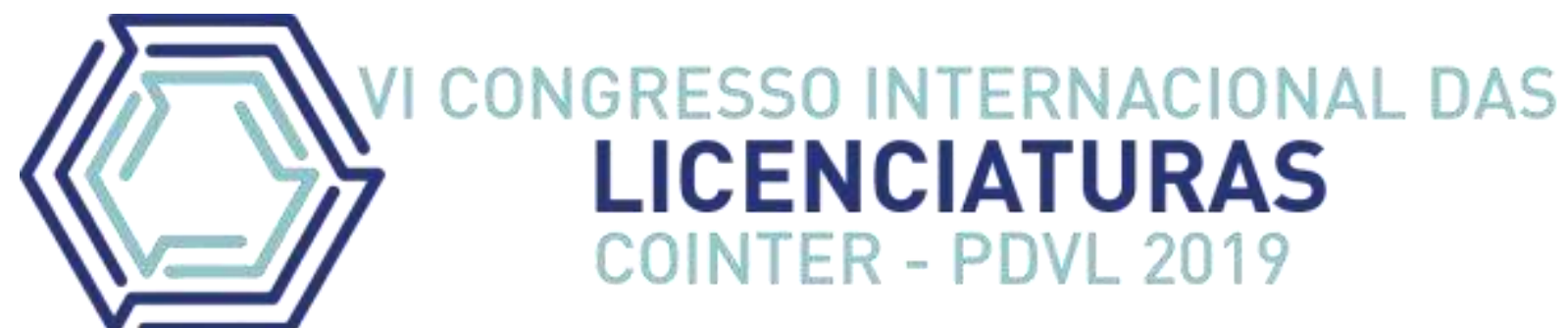

\title{
PRINCÍPIO FUNDAMENTAL DA CONTAGEM E MODELAGEM MATEMÁTICA NOS ANOS FINAIS DO ENSINO FUNDAMENTAL
}

\section{FUNDAMENTAL PRINCIPLE OF COUNTING AND MATHEMATICAL MODELING IN THE FINAL YEARS OF ELEMENTARY SCHOOL}

\author{
Apresentação: Comunicação Oral \\ Manassés da Silva Batista ${ }^{1}$; Tiago Gomes Sousa da Silva ${ }^{2}$; Amanda Karollyne do Nascimento \\ Santos ${ }^{3}$; Orientador: Alvino Alves Sant'Ana ${ }^{4}$;
}

DOI: https://doi.org/10.31692/2358-9728.VICOINTERPDVL.2019.0023

\section{Resumo}

O presente trabalho analisa a aplicação da Modelagem Matemática (MM) e os Princípios Fundamentais da Contagem (PFC), aplicado a pesquisa exploratória sobre voos de passagens aéreas, como uma proposta para favorecer o ensino e aprendizagem, por meio de pesquisas elaboradas por educandos dos anos finais do Ensino Fundamental. O objetivo foi criar um Ambiente de Aprendizagem utilizando a Modelagem Matemática na perspectiva de Barbosa (2001), seguindo as etapas de MM de Burak (2004). Assim, a MM tornou-se uma alternativa de ensino por meio de uma concepção que permite ao educador desenvolver uma busca pela interação proveniente da matemática contextualizada na realidade dos alunos. Os alunos foram convidados a realizarem uma pesquisa acerca de um tema voltado para a realidade utilizando os PFC. O objetivo da proposta foi oportunizar os alunos a compreender os PFC e sua utilização no dia a dia. Desse modo escolheram um tema específico e elaboraram uma pesquisa por meio de perguntas envolvendo problemas de PFC. Assim, por meio dos problemas, o raciocínio combinatório do educando foi valorizado, bem como seus conhecimentos prévios e estratégias em responder questões ligadas à sua realidade, possibilitando assim a interação professor-aluno e aluno-aluno. O trabalho é caracterizado como uma pesquisa qualitativa, baseado Bogdan \& Biklen (1994, p.16). As atividades tiveram duração de 10 horas e foi realizado com 4 alunos de uma escola pública de Porto Alegre, Rio Grande do Sul. As atividades desenvolvidas oportunizaram a criação de um Ambiente de Aprendizagem voltado ao cenário de investigação Skovsmose (2000), em que a MM teve um papel importante nesse processo de aprendizagem dos PFC.

\footnotetext{
${ }^{1}$ Mestrado em Ensino de Matemática, Universidade Federal do Rio Grande do Sul-UFRGS, manassess923@gmail.com

${ }^{2}$ Licenciatura em Matemática, Instituto Federal do Piauí- IFPI, tiagomat07@gmail.com

${ }^{3}$ Especialista em metodologia em Ensino de Matemática, Instituto Superior de Educação Programus- ISEPRO, mandy.karollyne16@gmail.com

${ }^{4}$ Doutor, Universidade Federal do Rio Grande do Sul-UFRGS, alvino@mat.ufrgs.br
} 
Palavras-Chave: PFC, Pesquisa exploratória, Modelagem Matemática, Ambiente de Aprendizagem.

\begin{abstract}
This paper analyzes the application of Mathematical Modeling (MM) and the Fundamental Principles of Counting (PFC), applied exploratory research on flight tickets, as a proposal to favor teaching and learning, through research developed by students of the final years of elementary school. The objective was to create a Learning Environment using Mathematical Modeling from Barbosa's perspective (2001), following the steps of Burak's MM (2004). Thus, MM has become a teaching alternative through a conception that allows the educator to develop a search for interaction from mathematical contextualized in students' reality. Students were invited to conduct research on a reality-oriented theme using the PFC. The purpose of the proposal was to enable students to understand the PFC and its use in everyday life. In this way they chose a specific theme and developed a survey through questions involving PFC problems. Thus, through the problems, the student's combinatory reasoning was valued, as well as your previous knowledge and strategies in answering questions related to your reality, thus enabling teacher-student and student-student interaction. The work is characterized as a qualitative research based on Bogdan \& Biklen (1994, p.16). The activities lasted 10 hours and were conducted with 4 students from a public school in Porto Alegre, Rio Grande do Sul. The activities developed enabled the creation of a Learning Environment focused on the research scenario Skovsmose (2000), where MM played an important role in this learning process of PFC.
\end{abstract}

Keywords: PFC, Exploratory research, Mathematical modeling, Learning environment.

\title{
Introdução
}

A escolha da temática, surgiu como é uma consequência das pesquisas realizadas no âmbito da disciplina de História da Educação Matemática no Programa de Pós-graduação Ensino de Matemática da Universidade Federal do Rio Grande do Sul (UFRGS), baseados na análise de livros didáticos de matemática: 1992 (Matemática 2: progressões, matrizes, progressões e Análise combinatória, geometria- 2º grau), em 2000 (Matemática: Uma nova abordagem), em 2005 (Matemática Completa), em 2015 (360 Matemática fundamental: Uma nova abordagem) pelos autores Giovanni, Giovanni Jr, Bonjorno, Paulo Câmara, sob a luz dos ambientes de aprendizagem Skovsmose (2000). Após as referidas pesquisas, percebi que os 
livros didáticos analisados, todos do Ensino Médio, em relação aos conteúdos de Análise Combinatória, em geral, das 388 questões analisadas, 378 estão relacionadas ao paradigma do exercício- Matemática pura e semi realidade Skovsmose (2000), representando aproximadamente $97,4 \%$. As questões voltadas para a realidade (questões com dados reais) são raras. Além disso, observei que a OBM (Olimpíada Brasileira de Matemática), a OBMEP (Olimpíada Brasileira de Matemática das Escolas Públicas e Privadas) e especialmente o ENEM (Exame Nacional do Ensino Médio) utilizam questões da realidade e semi realidade abrangendo conteúdos de análise combinatória, como: princípios aditivo e multiplicativo; combinação; permutação e arranjo. Observando os conteúdos programáticos do Ensino Fundamental voltado para matemática, percebi um distanciamento da forma como os conteúdos ligados à análise combinatória são trabalhados, por parte dos professores e por parte dos livros didáticos, em especial questões envolvendo os PFC (Princípios Fundamentais da Contagem).

Ainda, após algumas consultas realizadas em dissertações e teses, que tratam dessa temática, percebi que existem poucas pesquisas desenvolvidas envolvendo os PFC concomitantemente com a Modelagem Matemática (MM). Diante disso percebemos que seria desafiante aliar a Modelagem Matemática Barbosa (2001) e os PFC, alinhado com as etapas de Burak (2004), por meio de pesquisas que foram realizadas com os educandos dos anos finais do Ensino Fundamental.

\section{Fundamentação Teórica}

Apresentamos os Parâmetros Curriculares Nacionais (PCN) voltados para os Princípios Fundamentais da Contagem (PFC), MM na visão de Barbosa (2001) e as etapas de MM de acordo com perspectiva de Burak (2004).

\section{PCN voltados a Análise Combinatória}

Observamos que, de acordo com os PCN (Parâmetros Curriculares Nacionais) BRASIL (1997), o estudo dos PFC é recomendado desde os anos iniciais do Ensino Fundamental envolvendo situações simples de contagem. A ideia é a resolução de problemas por meio da criatividade do aluno, que pode ser apoiada em desenho de objetos com a utilização da soma ou multiplicação para problemas de contagem, que caracteriza uma importante ferramenta para 
o desenvolvimento lógico dedutivo. De acordo a pesquisa de Pessoa e Borba (2009), realizada com 99 estudantes do $2^{\circ}$ ao $5^{\circ}$ ano do Ensino Fundamental, os educandos desenvolvem compreensão e entendimento de problemas envolvendo raciocínio combinatório.

A Análise Combinatória começou a fazer parte dos PCN em 1997, inserido no tema “tratamento da informação". Desde o primeiro ciclo do Ensino Fundamental", os PCN em 1997 apresentam orientações didáticas a respeito de como ensinar Análise Combinatória por meio de associações com objetos "- Tendo duas saias — uma preta $(\mathrm{P})$ e uma branca $(\mathrm{B})$ - e três blusas - uma rosa (R), uma azul (A) e uma cinza $(\mathrm{C})$ - , de quantas maneiras diferentes posso me vestir?” (BRASIL, 1997, p.73). A ideia é a resolução do problema por meio da criatividade do aluno, que pode ser apoiada em desenho de objetos com a utilização da soma ou multiplicação- problemas de contagem.

Levando-se em conta tais considerações, pode-se concluir que os problemas cumprem um importante papel no sentido de propiciar as oportunidades para as crianças, do primeiro e segundo ciclos, interagirem com os diferentes significados das operações, levando-as a reconhecer que um mesmo problema pode ser resolvido por diferentes operações, assim como uma mesma operação pode estar associada a diferentes problemas. (BRASIL, 1997, p.73)

No segundo ciclo do Ensino Fundamental ${ }^{6}$ o aluno tem que se aprimorar nos conceitos de princípio multiplicativo, identificando as possíveis maneiras de combinar elementos de um determinado conjunto, pois o auxiliarão na criação de tabelas e gráficos.

Além disso, o emprego de problemas envolvendo combinatória leva o aluno, desde cedo, a desenvolver procedimentos básicos como a organização dos dados em tabelas, gráficos e diagramas, bem como a classificação de eventos segundo um ou mais critérios, úteis não só em Matemática como também em outros campos, o que reforça a argumentação dos defensores de seu uso desde as séries iniciais do ensino fundamental. (BRASIL, 1997, p.137)

Os PCN envolvendo análise combinatória no terceiro ciclo ${ }^{7}$ foram criados em 1998, com o objetivo de orientações didáticas voltadas para problemas de contagem, princípio multiplicativo e aditivo, podendo possibilitar o avanço dos conteúdos de probabilidade.

Relativamente aos problemas de contagem, o objetivo é levar o aluno a lidar com situações que envolvam diferentes tipos de agrupamentos que possibilitem o desenvolvimento do raciocínio combinatório e a compreensão do princípio multiplicativo para sua aplicação no cálculo de probabilidades. (PCN, 1998, p.52)

\footnotetext{
${ }^{5} \mathrm{O} 1^{\circ}$ Ciclo do Ensino Fundamental é o período escolar compreendido entre o $1^{\circ}$ e o $4^{\circ}$ anos.

${ }^{6} \mathrm{O} 2^{\circ}$ Ciclo do Ensino Fundamental é o período escolar compreendido entre o $5^{\circ}$ e o $7^{\circ}$ anos.

${ }^{7} \mathrm{O} 3^{\circ}$ Ciclo do Ensino Fundamental é o período escolar compreendido entre o $8^{\circ}$ e o $9^{\circ}$ anos.
} 
Os PCN de 1999 e os PCN+ de 2002, responsáveis pelas orientações didáticas do quarto ciclo $^{8}$, aborda maneiras de trabalhar a análise combinatória, voltado para o raciocínio combinatório por meio de resolução de situações problemas, discutindo que as fórmulas deve ser consequência da construção do modelo simplificado e explicativo da situação.

Espera-se que assim o aluno possa se orientar frente a informações de natureza estatística ou probabilística. Nesse contexto, as calculadoras e o computador ganham importância como instrumentos que permitem a abordagem de problemas com dados reais ao mesmo tempo que o aluno pode ter a oportunidade de se familiarizar com as máquinas e os softwares. Este tema estruturador permite o desenvolvimento de várias competências relativas à contextualização sociocultural, como a análise de situações reais presentes no mundo contemporâneo e a articulação de diferentes áreas do conhecimento. Contribui identificação de regularidades, interpretação e uso de modelos matemáticos e conhecimento de formas específicas de raciocinar em Matemática. (BRASIL, 2002, p.126,127.)

A aprendizagem contextualizada, preconizada pelos PCN, visa que o educando aprenda as competências para solucionar problemas com contextos apropriados. Diante disso, a proposta de trabalhos interdisciplinares, visa fortalecer e valorizar os conhecimentos e experiências vividas pelos educandos dentro e fora do contexto escolar.

Os PCN envolvem os quatro ciclos que compreende o Ensino Infantil, Ensino Fundamental I, Ensino Fundamental II e Ensino médio quando se trata da análise combinatória. Os problemas e orientações propostos pelos PCN, tratam os problemas por meio de questões ligada ao cotidiano. Conteúdos como os Princípios Fundamentais de Contagem, arranjos, combinação simples, permutação simples e permutação com elementos repetidos, podem ser aplicados baseados em dados reais ou tentativas de reprodução da realidade, e que por meio da resolução de problemas, podem ser resolvidos com criatividade, por parte do aluno, associando os problemas propostos ao cotidiano.

Durante essa pesquisa, percebemos que houve mudanças nos livros didáticos, com a implementação dos PCN. Apesar dos PCN contar com orientações didáticas, as escolas foram impactadas de maneira a observar e trabalhar em consonância com as propostas dele.

\footnotetext{
${ }^{8} \mathrm{O} 4^{\circ}$ Ciclo do Ensino Médio é o período escolar compreendido entre o $1^{\circ}$ ao $3^{\circ}$ anos.
} 


\section{Modelagem Matemática}

Segundo Barbosa (2001), MM é um Ambiente de Aprendizagem no qual os alunos são convidados a indagar ou investigar, por meio da matemática, situações ou problemas oriundos de outras áreas da realidade.

Ainda, Barbosa (2001) classifica a prática da MM em três casos, levando em consideração a apresentação do problema, a atuação do professor e alunos na busca pela resolução, a interação do professor com alunos nas atividades:

Caso 1- O professor apresenta a descrição de uma situação-problema, com as informações necessárias à sua resolução e o problema formulado, cabendo aos alunos o processo de resolução.

Caso 2- O professor traz para a sala um problema de outra área da realidade, cabendo aos alunos a coleta das informações necessárias à sua resolução.

Caso 3- A partir de temas não-matemáticos, os alunos formulam e resolvem problemas. Eles também são responsáveis pela coleta de informações e simplificação das situações-problema. É via do trabalho de projetos.

A tabela a seguir, feita por Barbosa $(2001$, p.9) esclarece a relação de professor-aluno nos casos de Modelagem:

Figura 1- O aluno e o professor nos casos de Modelagem Matemática
Caso 1
Caso 2
Caso 3

\begin{tabular}{l|c|c|c}
$\begin{array}{l}\text { Elaboração da situação- } \\
\text { problema }\end{array}$ & professor & professor & professor/aluno \\
\hline Simplificação & professor & professor/aluno & professor/aluno \\
\hline $\begin{array}{l}\text { Dados qualitativos e } \\
\text { quantitativos }\end{array}$ & professor & professor/aluno & professor/aluno \\
\hline Resolução & professor/aluno & professor/aluno & professor/aluno \\
& & &
\end{tabular}

Fonte: Barbosa, 2001, p.9. 
Chaves e Lorenzoni destacam:

O trabalho com modelagem matemática também permite que se rompa com os dispositivos táticos e estratégicos do Ensino Tradicional de Matemática, abrindo então espaço para novos cenários pautados na investigação e no trabalho colaborativo e participativo envolvendo alunos e professores. No viés da modelagem matemática, enquanto estratégia de ensino, o aluno se envolve, pesquisa, participa, inquire, toma as rédeas da situação, tonando-se assim um indivíduo ativo, participativo, responsável e ciente de seus atos (CHAVES; LORENZONI, 2010, p. 10).

Os problemas criados pelos estudantes poderão proporcionar maior desenvoltura no desenvolvimento do trabalho. Diante disso, o trabalho com os PFC e MM poderá proporcionar maior interação, bem como maior segurança para enfrentar e superar os desafios da pesquisa. De acordo com o Burak (2004):

A Modelagem enseja, ainda de forma natural e indissociável, o ensino e a pesquisa, pois ao trabalhar com temas diversos, de livre escolha do grupo ou dos grupos, favorece a ação investigativa como forma de conhecer, compreender e atuar naquela realidade. Não se pode intervir, de forma adequada, numa realidade que não se conhece. Assim, ao trabalhar um tema, procura-se conhecer as várias dimensões ou aspectos envolvidos que compõem essa realidade. (BURAK, 2004, p. 5).

Ainda, a partir das propostas feitas por Barbosa, segundo Brumano (2014), "em trabalhos com a MM o aluno deve ser convidado a se integrar e pesquisar, inserindo-se ao ambiente de aprendizagem que a Modelagem Matemática proporciona”.

Portanto, por meio do convite para a participação em nosso Projeto de MM envolvendo os PFC, queremos propiciar um Ambiente de Aprendizagem, por meio de um trabalho colaborativo, com a participação dos alunos na elaboração e resolução de problemas.

Perspectiva de Burak

Para Burak (2004), a MM é uma alternativa metodológica para o ensino de matemática, que depende fundamentalmente do interesse do grupo-alunos. Podendo resultar em uma maior motivação e consequentemente, na melhoria do processo ensino e de aprendizagem, tornando 
os alunos corresponsáveis por suas aprendizagens e oportunizando o estabelecimento de relações afetivas professor-aluno, que passa a ser um mediador entre o conhecimento matemático e o conhecimento do aluno.

Burak (2004, p.3) estabelece cinco etapas para se trabalhar a MM: 1- Escolha do tema; 2- Pesquisa exploratória; 3- Levantamento dos problemas; 4- Resolução dos problemas; e 5Análise crítica das soluções. Cada uma das etapas tem a participação do professor e aluno. A primeira etapa o professor tem que criar condições e incentivar para que os alunos possam escolher o tema sobre o qual farão a pesquisa. O tema deverá ser de interesse do aluno e fazer parte do seu cotidiano. De acordo com (KLÜBER e BURAK, 2008, p. 21), "uma vez que não necessitam ter nenhuma ligação imediata com a Matemática ou com conteúdo matemáticos e sim com o que os alunos queiram pesquisar".

Na segunda etapa que é a pesquisa exploratória, os alunos vão a campo a procurar materiais e dados teóricos suficientes para embasar a pesquisa, os registros nessa etapa é importante, pois por meio deles os problemas surgirão. No entanto, na pesquisa é essencial colher o maior número de informações possíveis e noções prévias que se quer desenvolver, pois melhor será a análise dos dados posteriormente. "A pesquisa de campo é fundamental, pois o contato com o ambiente é um ponto importante do trabalho com a Modelagem e ajuda o aluno a desenvolver aspectos formativos, investigativos" (KLÜBER e BURAK, 2007, p.3).

$\mathrm{Na}$ terceira etapa, de levantamento dos problemas, os alunos apresentam todos os materiais e dados reais colhidos na etapa anterior. A partir disso, "os alunos elaboram e esquematizam os problemas surgidos sobre o tema" (SOISTAK e BURAK, 2005b). Importante etapa para questionar e investigar de acordo com os dados coletados, como afirma (KLÜBER e BURAK, 2007, p. 3) "essa fase da Modelagem é muito rica, pois desenvolve no aluno a capacidade de tomar decisões, de formular hipóteses, de questionar as várias possibilidades de resolução de um mesmo problema”.

Na quarta etapa é a resolução dos problemas que consiste em desenvolver o conteúdo matemático de acordo com o tema, dando condições necessárias para resolver os problemas levantados na etapa anterior. De acordo com Burak (1987, 1992), essa etapa tem como objetivo explicar matematicamente situações do cotidiano das pessoas, ajudando-as a fazer predições e tomar decisões.

Na quinta etapa da análise crítica da solução é uma etapa importante, pois é "nesse momento que se analisa e se verifica a relação e a validação da resolução encontrada para o 
problema” (SOISTAK e BURAK, 2005b, p. 3). A reflexão sobre os resultados obtidos na pesquisa e no processo podem melhorias das decisões e ações. Ela, também, "contribui para a formação de cidadãos participativos, mais autônomos que auxiliem na transformação da comunidade em que participam" (KLÜBER e BURAK, 2007, p.4). A seguir apresentamos as principais palavras chaves das 5 etapas de Burak (2004):

Figura 2- Palavras chaves das etapas de MM de (BURAK,2004)

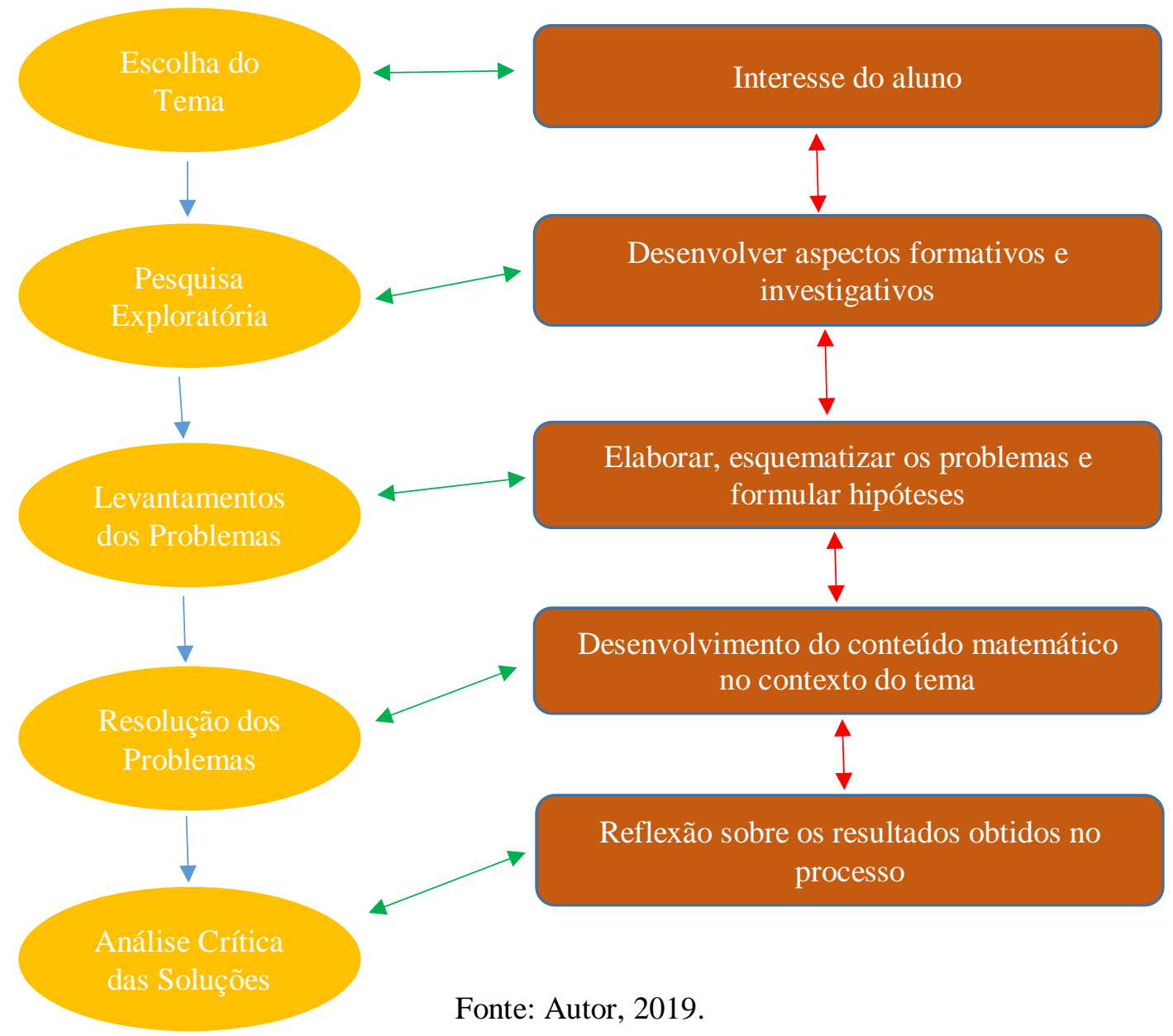




\section{Metodologia}

Segundo Bogdan \& Biklen (1994, p.16), a pesquisa é caracterizada como qualitativa, pois a nossa fonte de coleta de dados envolveu registros em cadernos, imagens, conversas, notas de campo, fotografias e citações. A pesquisa será exploratória, pois será baseada e sustentada pelas cinco etapas mencionadas por Burak (2010): escolha do tema, pesquisa exploratória, levantamento dos problemas, resolução dos mesmos e o desenvolvimento da matemática relacionada ao tema e análise crítica das soluções. Dessa forma, de acordo com Burak (2010), a pesquisa exploratória deve acontecer de forma natural, orientada pelo simples desejo dos educandos em conhecer melhor o assunto.

Para realizar essa pesquisa, convidamos alguns 4 alunos do $9^{\circ}$ ano do Ensino Fundamental da Escola pública de Porto Alegre. As atividades foram realizadas no turno das aulas, a participação dos alunos foi voluntária.

As atividades desenvolvidas seguiram três etapas, cada etapa com objetivos e cronograma específicos. No total foram 10 horas aulas, na primeira etapa com duração de 3 horas, na segunda etapa com duração de 4 horas na terceira etapa com duração de 3 horas. $\mathrm{Na}$ primeira, apresentamos as atividades e algumas sugestões de temas a serem trabalhados, por meio de pesquisas exploratórias e pesquisas de campo, a serem realizadas pelos alunos. Também incentivamos os participantes na busca de outros temas de seus interesses. Nessa etapa os alunos ficaram responsáveis pela elaboração de um roteiro de perguntas que estivessem alinhadas com o uso dos PFC, de acordo com o tema escolhido. Os temas sugeridos foram: cardápios em restaurantes, escolhas de livros na biblioteca da escola, senhas de desbloqueio de celulares, combinação em placas de carro.

\section{Resultados e Discussão}

A seguir, apresentaremos o diálogo entre o professor pesquisador e os alunos a respeito da pesquisa sobre escolhas de passagens aéreas realizadas pelos alunos. Logo em seguida discutiremos os resultados encontradas de acordo com os referenciais teóricos. 
Passagens aéreas

Diante das sugestões propostas pelo professor pesquisador, os alunos sugeriram o tema sobre passagens aéreas, pois tiveram como motivação viagens à casa de parentes, cujo trajeto é feito de avião. Primeiramente, fizeram levantamentos sobre a distância e temporadas de preços durante o ano. O trecho escolhido foi de São Paulo a Minas Gerais, no mês de junho de 2019. De acordo com a pesquisa, a distância de São Paulo a Minas Gerais é de 691 km, e o tempo de voo é, em média, de 54 minutos.

Além disso os alunos detalham os preços das passagens durante cada mês do ano de 2019 da companhia Azul, colocando em evidência o voo mais barato e o voo mais rápido. O próximo passo, realizaram outros levantamentos de trechos de Companhias Aéreas e calculou a quantidade de maneiras totais para a realização da viagem, fazendo uma melhor economia e utilizando os voos mais rápidos. Assim, escolheram duas Companhias aéreas (Azul e Gol), em um dia de junho os voos mais econômicos, e verificaram que de São Paulo a Belo Horizonte havia 4 voos da Azul e 5 voos da Gol, de Belo Horizonte a São Paulo tinha 4 voos da Azul e 6 voos da Gol. Então foi feita as discussões na sala de aula, sobre quantas maneiras para ir e voltar de São Paulo a Belo Horizonte. A seguir alguns trechos de diálogos, chamaremos os alunos que participaram da pesquisa de Aluno A, Aluno B, Aluno C e Aluno D.

Prof. Pesq:: Quantas maneiras totais para fazer a Viagem de belo Horizonte a São Paulo?

Aluno A: 19 maneiras

Aluno B.: São 19, pois 4+5+5+4+6 é 19.

Neste momento todos os alunos concordaram. Foi pedido para que um aluno fosse a lousa mostrar as possibilidades.

Prof. Pesq: Vamos verificar se o raciocínio está certo. Algum de vocês para vir a lousa mostrar?

Aluno C:. Eu vou. O pessoal vai me ajudar professor.

Prof. Pesq: A Azul tem quantos voos de ida e volta de São Paulo a Belo horizonte?

Aluno B:. 4 voos de ida e 4 voos de volta.

Aluno D:. Então identifica os voos de ida e volta da Azul. 
Aluno A:. Vou chamar os voos de ida de A1, A2, A3 e A4. Os voos de volta de V1,V2,V3 e V4. Prof. Pesq: Escolham um voo de ida.

Aluno C:. Tem que ser na ordem?

Prof. Pesq: Qualquer um.

Aluno B:. Escolhe o A2 para ir.

Aluno C:. Vou marcar o A2.

Prof. Pesq. Já que vocês escolheram o voo A2 para ir. Quantos voos pode-se voltar?

Aluno A: de V1,V2,V3 e V4.

Assim foi feito pelo aluno C ligações de acordo com as escolhas de ida e volta. Dando continuidade ao raciocínio.

Aluno C:. Assim, se for de A1 a pessoa tem 4 opções para voltar, se for de A2 também terá 4 opções para voltar, e assim também para o A3 e A4. Indo de Azul e Voltando de Azul ele terá $4+4+4+4=16$ maneiras.

Figura 3- Indo Azul e Voltando de Azul

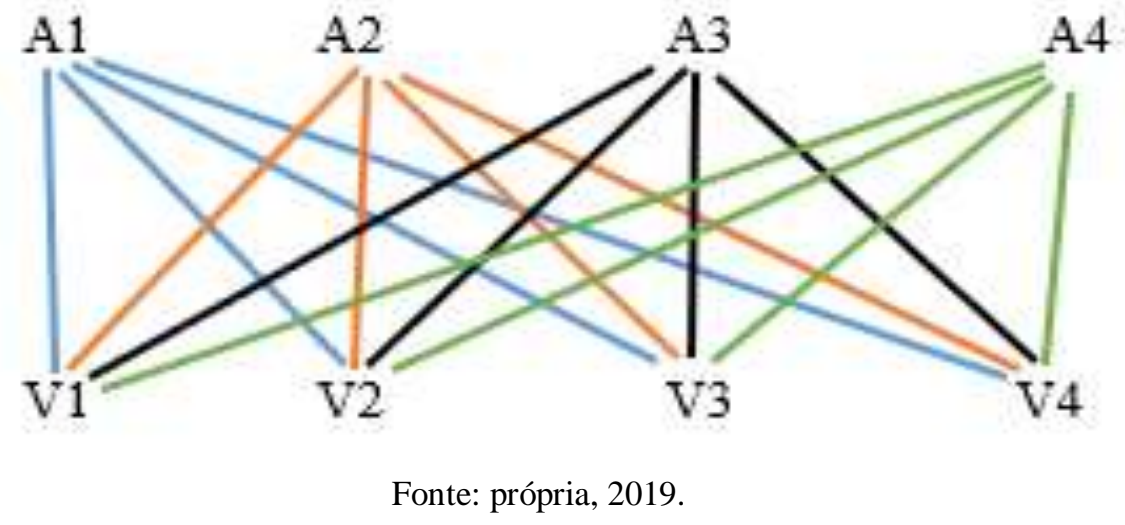

A próxima relação que os alunos fizeram por meio da arvore de possibilidades foi indo de Gol e voltando de Gol. Nomeando os voos de ida de G1, G2, G3, G4 e G5, os voos de volta de GV1, GV2, GV3, GV4, GV5 e GV6. Utilizando o princípio aditivo os alunos somaram 6+6+6+6+6 = 30 maneiras, Indo de Gol e voltando de Gol de São Paulo a Belo Horizonte. 
Figura 4- Indo de Gol e voltando de Gol

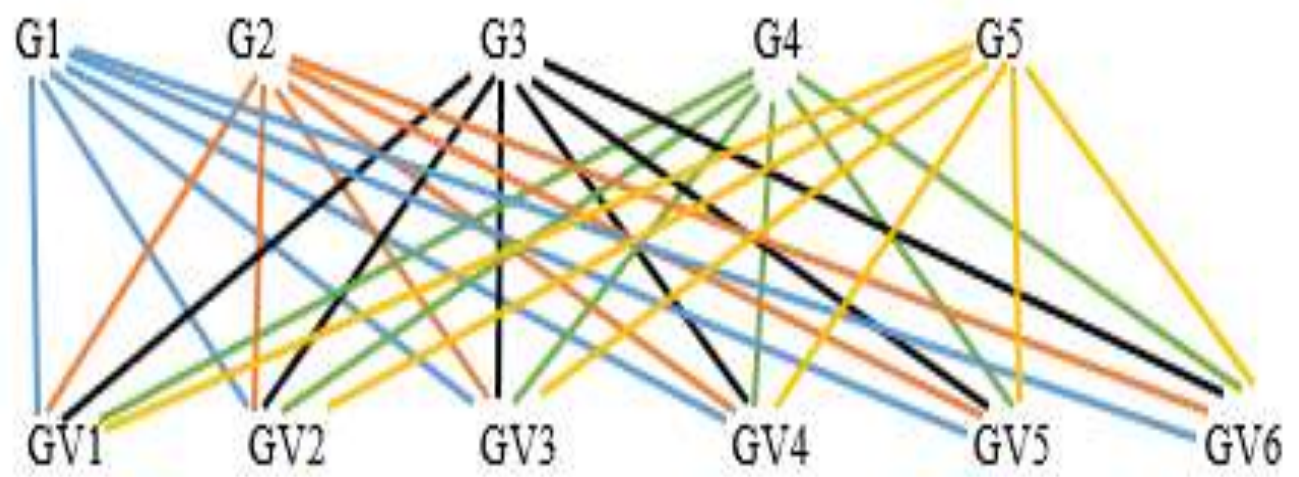

Fonte: própria, 2019.

Os alunos deram continuidade ao raciocínio, e por meio da árvore de possibilidades calcularam a quantidade de maneiras indo de Azul e voltando de Gol (Figura 5), somando 6+6+6+6 =24 maneiras. Assim como indo de Gol e voltando de Azul (Figura 6), os alunos somaram $4+4+4+4+4=20$ maneiras.

Figura 5- Indo de Azul e voltando de Gol

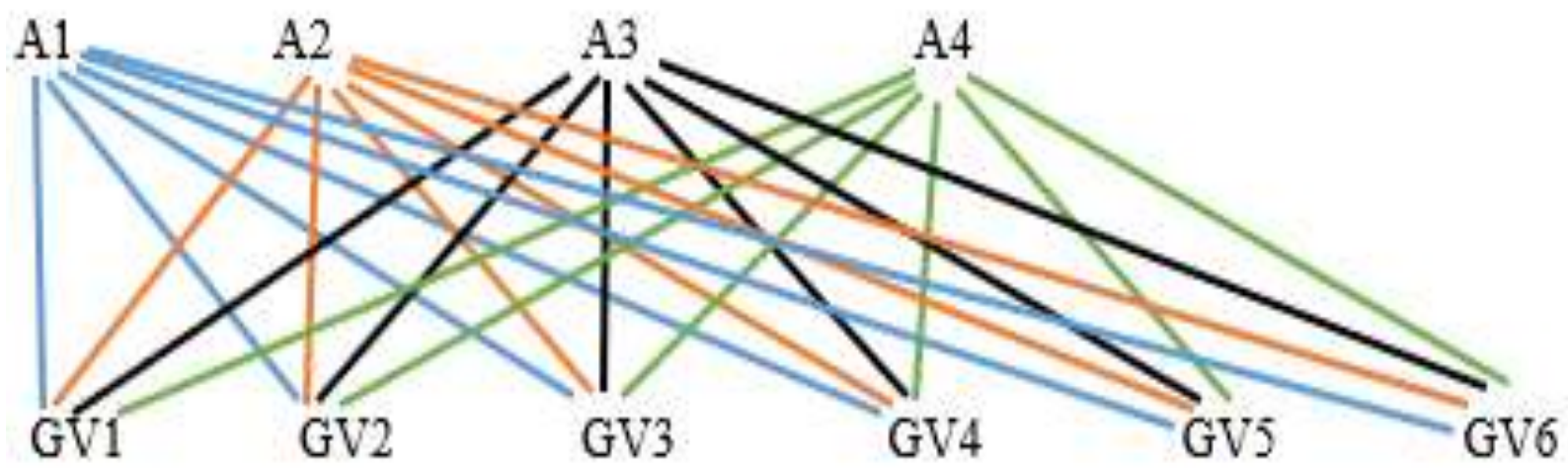

Fonte: própria, 2019. 


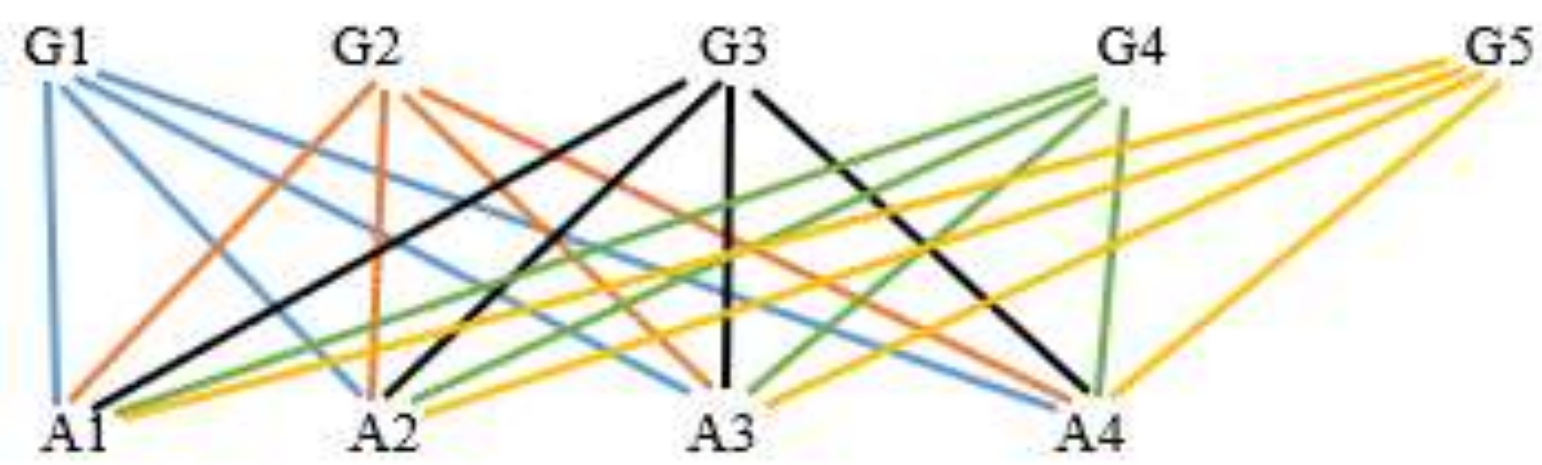

Fonte: própria, 2019.

Prof. Pesq: Quantas maneiras no total?

Aluno B:. Agora é só somar 16+30+24+20=90 maneiras.

Prof. Pesq: Teria outra maneira para fazer esse cálculo?

Aluno D:. Não vejo outra forma.

Aluno C: Pode só multiplicar $9 \times 10=90$ maneiras.

Prof. Pesq: Por quê?

Aluno C: o 9 representa a quantidade de voos de ida e o 10 os voos de volta.

Prof. Pesq:. Então isso quer dizer que a escolha de ida não interfere na escolha de volta, pois são eventos independentes.

Prof. Pesq:.O que vocês aprenderam por meio desta pesquisa exploraria?

Aluno C:. Além de aprender agora o número maneiras. Também aprendi que temos que pesquisar, pois geralmente as agências vendem passagem acima do preço.

Primeiramente, de acordo com os diálogos, os alunos falaram que teria 19 maneiras para ir e voltar de São Paulo a Belo Horizonte, porém foram indagados e incentivados a escrever passo a passo, relacionando primeiramente um voo da Azul de ida com os voos da Azul de volta de São Paulo a Belo Horizonte, e continuando neste processo descobriram que a quantidade de maneira iria além do que eles imaginavam. Assim perguntei se teria outras maneiras para fazer o cálculo, os alunos foram tentando relacionar os voos de ida com os voos de volta, assim por meio de tentativas e erros relacionado ao pensamento combinatório, descobriram que teria 9 
voos para ir e 10 voos para voltar e concluíram que no total teriam 9x10 = 90 maneiras no total, de São Paulo a Belo Horizonte.

As atividades desenvolvidas por meio das etapas de Burak (2010), auxiliou os alunos na tomada de decisão sobre o desenvolvimento das atividades, pois por meio do interesse dos alunos, houve a escolha do tema que não foi sugerido pelo professor pesquisador. A pesquisa exploratória se deu em um ambiente ligado a realidade do aluno-internet, e o tema de pesquisa relacionado ao cotidiano que é vivido por um aluno todo ano que realiza viagens aéreas de São Paulo a Minas Gerais. Por meio das etapas de Burak (2010), houve o momento na pesquisa que os alunos investigaram, desde os preços das passagens, as Companhias Aéreas e a quantidade de maneiras para a realização do trecho escolhido. Assim, a pesquisa culminou na resolução do problema proposto que se deu por meio da análise da questão proposta, e a análise crítica trouxe resposta que os alunos não imaginava existir, comparando a resposta do diálogo inicial, quando todos os alunos concordaram com a afirmação do "Aluno B:.São 19, pois 4+5+5+4+6 é 19". Se referindo que a quantidade total de maneira era só somar a quantidade de voos de ida e volta. Enquanto depois de todo o processo de construção chegaram a conclusão: "Aluno C:. Pode só multiplicar $9 \times 10=90$ maneiras. $O 9$ representa a quantidade de voos de ida e o 10 os voos de volta”. Utilizando em todo o processo os princípios aditivo e multiplicativo.

De acordo com Barbosa (2001), há três casos do aluno e o professor para atividades de MM (Figura 1). No início, pretendia-se trabalhar com o caso 2, que é quando somente o professor elabora a situação problema, neste caso o tema para a investigação. Porém, o trabalho seguiu de acordo com o tema escolhido pelos alunos, auxiliados pelo professor. No início os alunos começaram fazendo levantamentos sobre os tópicos, porém ainda não tinham uma ideia clara de como proceder, isto foi evidenciado quando no início da pesquisa, eles fizeram o levantamento da distância e a quantidade de horas que de um voo de São Paulo a Minas Gerais, não focando nas possibilidades de voos das Companhias Aéreas. A associação da matemática com o mundo real para Barbosa (2001) é uma fonte rica para o ensino e aprendizagem da matemática em sala de aula.

[...] oportunidade para os alunos indagarem situações por meio da Matemática sem procedimentos fixados previamente e com possibilidades diversas de encaminhamento. Os conceitos e ideias matemáticas exploradas dependem do encaminhamento que só se sabe à medida que os alunos desenvolvem a atividade. (BARBOSA, 2001, p. 05). 
Portanto, a simplificação do problema proposto, na elaboração e pesquisa do tema, foi pesquisada exclusivamente pelos alunos Barbosa (2001), e o professor orientou sobre explorarem locais para viagens, quantidade de voos de Companhias Aéreas em datas específicas. A resolução como evidenciada nos diálogos acima mostrou que os alunos estavam com uma visão equivocada em relação a quantidade totais de maneiras de acordo com a pesquisa que fizeram levando em consideração os voos da Azul e da Gol, porém o professor sugeri-os escolher somente um voo de ida e assim ver quantas opções de volta teriam, e assim por diante, até chegarem nas 90 maneiras, que seriam 9 voos de ida e 10 voos de volta de São Paulo a Belo Horizonte.

As atividades desenvolvidas, oportunizaram o aprendizado por meio das discussões em um Ambiente de Aprendizado ligado a realidade do aluno Skovsmose (2000), por meio de um tema não matemático. De acordo com as pesquisas iniciais dos alunos, que os encaminhamentos foram dados, com o objetivo de se estudar os Princípios Fundamentais da Contagem- Princípio aditivo e Princípio Multiplicativo.

\section{Conclusões}

As atividades desenvolvidas com os alunos por meio das etapas de Burak (2004), propiciaram um Ambiente de Aprendizagem voltado para um cenário de investigação Skovsmose (2000). A escolha do tema pelos alunos, proporcionou para que despertassem o interesse sobre a temática (passagens aéreas), pois todos os alunos já teriam vivenciado essa realidade em algum momento da vida. A interação do professor pesquisador e dos alunos se deu por meu do caso 3 Barbosa (2001), pois todas as etapas ambos se envolveram no trabalho desenvolvido, sendo que os alunos fizeram toda a parte da pesquisa exploratória sob a orientação do professor pesquisador.

Considerando os resultados alcançados, como: discussões entre os alunos e o professor pesquisador; criação de um Ambiente de Aprendizagem pautado na Modelagem Matemática por meio do cenário de investigação e Aprendizagem por meio da interação do aluno-aluno e aluno- professor. Assim, os alunos são protagonistas e da sua aprendizagem, desde o momento da pesquisa exploratória até as discussões dos dados levantados pelos alunos sob a orientação 
do professor. As contribuições do professor pesquisador em sala de aula, dando total apoio e incentivo nas atividades, foram uteis para: o desempenho estudantil, a experiência vivenciada e para os relatos colhidos. Os resultados apontam que a utilização de MM para o ensino dos PFC, obedecendo as etapas de MM de Burak (2004) no caso 3 de Barbosa (2001), possibilita aulas de matemática mais interativas, de forma que todos possam participar de maneira ativa e tenham acesso ao processo de ensino/aprendizagem na construção do conhecimento.

\section{Referências}

BARBOSA, Jonei Cerqueira. Modelagem na Educação Matemática: contribuições para o debate teórico. In: REUNIÃO ANUAL DA ANPED, 2001, Caxambu.

BARBOSA, J.C; CALDEIRA, A.D.; ARAÚJO, J.L. Modelagem Matemática na Educação Matemática Brasileira: pesquisas e práticas educacionais. Biblioteca do Educador Matemático - Coleção SBEM, v.3. Recife: SBEM, 2007. 256 p. p. 33-47; 99-114.

BOGDAN, R.; BIKLEN, S.K. Investigação Qualitativa em Educação: uma introdução a teória e aos métodos. Porto, Portugal: Editora Porto, 1994.

BURAK, D. Modelagem matemática: ações e interações no processo de ensino aprendizagem. 1992. Tese (Doutorado em Educação) - Universidade Estadual de Campinas, Campinas, 1992. BURAK, D. Modelagem matemática e a sala de aula. In: Encontro Paranaense de Modelagem em Educação Matemática, 1, 2004, Londrina, Anais... Londrina: [S.I], 2004.

BURAK, D. Modelagem Matemática sob um olhar de Educação Matemática e suas implicações para a construção do conhecimento matemático em sala de aula. Revista de Modelagem Na Educação Matemática, Blumenal, v. 1, n. 1, p.10-27, 2010. 
BURAK, D.; KLÜBER, T. E. Modelagem Matemática na Educação Básica: uma trajetória. In: Encontro Nacional de Educação Matemática, IX, Belo Horizonte, 2007. Anais... Belo Horizonte: Sociedade Brasileira de Educação Matemática, p. 1-19, 2007 a.

BRASIL. Secretaria de Educação Fundamental. Parâmetros Curriculares Nacionais. Matemática. $1^{\circ}$ e $2^{\circ}$ ciclos. Brasília: MEC/SEF, 1997.

BRASIL. Secretaria de Educação Fundamental. Parâmetros Curriculares Nacionais. Matemática. 3º $4^{\circ}$ ciclos. Brasília: MEC/SEF, 1998.

BRASIL. Ministério da Educação. Secretaria de Educação Média e Tecnológica. Parâmetros Curriculares Nacionais: Ensino Médio: Ciências da Natureza, Matemática e suas Tecnologias. Brasília: MEC, 1999.

BRASIL, Secretaria da Educação Média e Tecnológica. PCNEM: Parâmetros Curriculares Nacionais para o Ensino Médio. Brasília: MEC, 2002-a.

BRASIL, Secretaria da Educação Média e Tecnológica. PCN: Parâmetros Curriculares Nacionais. Brasília: MEC, 2002-c.

BRASIL, Secretária da Educação Média e Tecnológica. PCN+: Ensino médio-orientações educacionais complementares aos parâmetros Curriculares Nacionais. Brasília: MEC, 2002-b.

BRASIL, Secretaria da educação Básica. Orientações Curriculares para o Ensino Médio: Ciências da Natureza, Matemática e suasTecnologias.Brasília, MEC,2006-a.

BRUMANO, Cleuza. A modelagem matemática como metodologia para o estudo de análise combinatória. Juiz de Fora: UFJF, 2014. 153 p. Dissertação de Mestrado ProfissionalPrograma de Pós-Graduação em Educação Matemática, Universidade Federal de Juiz de Fora, Minas Gerais, 2014. 
CHAVES, Rodolfo; LORENZONI, Luciano Lessa. Modelagem matemática: concepções e tutores do multicurso matemática. Salvador: Anais do X ENEM, 2010.

PESSOA, C.; BORBA, R. Quem dança com quem: o desenvolvimento do raciocínio combinatório de crianças de $1^{\mathrm{a}}$ a $4^{\mathrm{a}}$ série. Zetetiké, Cempem- FE - Unicamp, v. 17, n. 31 jan/jun. 2009.

SKOVSMOSE, Ole. Cenários para investigação. Bolema, São Paulo, v.13, n.14, p. 66-91. 2000 .

SOISTAK, A. V. F.; BURAK, D. O conhecimento matemático elaborado via metodologia alternativa da Modelagem Matemática. In: Congresso Internacional de Ensino da Matemática, III, Canoas, 2005. Anais... Canoas: ULBRA, p.1-6, 2005a. 